\section{Representation of dental care and oral health in children's drawings}

\author{
D. D. Torriani, ${ }^{* 1}$ M. L. Goettems, ${ }^{1}$ M. G. Cademartori, ${ }^{2}$ R. R. Fernandez ${ }^{3}$ \\ and D. M. Bussoletti ${ }^{4}$
}
IN BRIEF
- Demonstrates that drawings can be used as a tool to understand children's emotions and expectations about dental treatment.
- Provides information on children's dental perception of dental treatment and oral health.
- Aids understanding of what children may see as unpleasant about going to the dentist and the importance of drawings to facilitate communication with patients.

\begin{abstract}
Background Paediatric dentistry requires knowledge of preventive measures, restorative skills and an understanding of child development. Aim This exploratory, descriptive and qualitative study has analysed children's drawings regarding their perception of dental treatment and oral health. Method Children aged from six to ten years attending a dental school for treatment were randomly invited to create a drawing about 'dental treatment' and 'oral health'. Verbal expressions made by the children whilst drawing were also recorded and attached to the drawings. These representations were analysed and categorised using Vygotsky postulations for context reading. Discussion During the drawing analysis different themes emerged. Five categories regarding perceptions of dental treatment were identified: personal relationship; power relation; trauma; childhood resistance; and contextualisation of dental care in the child's life. Three categories relating to oral health were determined: dichotomy of health/sickness; ludic representation of health; and sickness seen as a process. Conclusion Drawing can be used to understand children's emotions and expectations about dental treatment. Besides possessing technical skills and scientific knowledge, dentists have an obligation to pay attention to children's feelings.
\end{abstract}

\section{INTRODUCTION}

Paediatric dentistry requires both knowledge of preventive measures and restorative skills in addition to an understanding of child psychological development. This understanding enables dentists to deal with potentially stressful situations in the dental environment and to identify dental anxiety and fear. Thus, the dental profession needs to be aware of patient perceptions, preferences and fears in order to meet patient needs and provide them with quality care in a manner that is comforting and reduces anxiety. ${ }^{1}$

Studies have been carried out to assess child perception about dental treatment, ${ }^{2-6}$ and it is recognised that the majority of oral health research is conducted on children rather than with them. ${ }^{7}$ As more weight is given to the rights and views of the child, there has been a shift towards research with children and the adoption of the concept of child-centred research. ${ }^{7}$

'Department of Social and Preventive Dentistry and Post-Graduate Program in Dentistry, Federal University of Pelotas, Brazil; ${ }^{2}$ Post-Graduate Student, Post-Graduate Program in Dentistry, Federal University of Pelotas, Brazil; ${ }^{3}$ Dentist in Private Clinic, Porto Alegre, Brazil; ${ }^{4}$ Department of Educational Foundations, School of Education, Federal University of Pelotas, Brazil

Online article number E26

Refereed Paper - accepted 16 December 2013

DOI: $10.1038 /$ sj.bdj.2014.545

${ }^{\circ}$ British Dental Journal 2014; 216: E26
For this purpose, tools have been developed for the measurement of the emotional status of children in dental clinics, including nonverbal self-report techniques. ${ }^{2} \mathrm{~A}$ simple and convenient method to measure children's perception is based upon their drawings, before and during the treatment course. ${ }^{8,9}$ Drawings are, for Vygotsky, examples of first order symbolisation. When a child draws they embody the image they have created internally to handle their emotions. This confirms the idea that, through the materialisation, the child knows, organises and develops their emotions. ${ }^{10}$

Drawings are easy to obtain, as most children enjoy this task. They can be used to reveal thoughts and feelings that possibly could not be expressed through speech or written methods. ${ }^{11}$ Moreover, drawings are advantageous in that they are usually non-directive, non-threatening, require no simple right answers, and help to identify feelings and desires that subjects may not be consciously aware of or able to express verbally. ${ }^{2}$

Understanding the way children think about dentistry can help dentists to better shape their practice to meet the preferences and needs of their patients. In order to contribute to a debate about the importance of hearing the voice of the child at the dentist, this study attempted to analyse children's perceptions about dental treatment and oral health concepts based on their drawings combined with subsequent verbal comments.

\section{METHODS}

This exploratory and qualitative-approach study was approved by the Human Research Ethics Committee of the Federal University of Pelotas under protocol number 37/07. Parents were informed of the study aims by one of the authors and all signed informed consent forms. All children aged six to nine years old, attending the infant clinic unit of the Dental School of Federal University of Pelotas in the course of one month were randomly invited to participate. In this clinic, children are treated by dental students under the supervision of their teachers. Children with cognitive impairment were excluded. This age range was chosen according to Piaget's theory of cognitive development, which indicates that art ceases as a spontaneous activity by ten years of age. ${ }^{12}$ This study consisted of applying a projective technique of self-report: the thematic drawing. This activity was implemented and analysed by a psychologist (DMB, PhD in psychology).

While waiting for the treatment session, the children were instructed to draw two pictures linked to the following questions: 1) What do you remember about attending the dentist? 2) Draw what you consider to be a healthy and a non-healthy mouth. A 
set of similar supplies was given to each child, including blank A4 sheets of paper, an eraser, coloured pencils and graphite pencil. Children had about 15 minutes to do the drawings. In the event that the child was very distracted, the directions had to be repeated and encouragement to participate was given. Parents were instructed not to influence the children to respond one way or the other.

While performing the drawing, verbal expressions made by the children were recorded, as sources for analysis. Verbal expressions made by the children were attached to the drawings. Information on the child's medical and dental history was collected from the parents to assess possible influences on the child's perception of dental treatment.

The drawings were analysed by a psychologist (DMB), who categorised them using Vygotsky postulations for context reading. Verbal expressions made by the children were used along with anamnestic data and the drawings as sources for analysis within the categorical model (considering the fact that children had underwent dental treatment and were asked to represent their feeling regarding this environment). Application and determination criteria validated by the council for the supervision and regulation of class in Brazil, the CFP (Federal Council of Psychology), were adopted.

\section{RESULTS}

All parents and children invited agreed to participate in this study. A total of 15 children (6-9 years of age) with the mean age of 7.53. Seven males (46.7\%) and eight females (53.3\%) participated in the study. During the drawing analysis, five different categories were identified for dental treatment and three for the oral health.

\section{Dental treatment}

The following dental treatment categories emerged:

\section{1) Personal relationship}

Drawings $1 \mathrm{a}$ and $1 \mathrm{~b}$ (Fig. 1) show the 'human' professional strongly represented, with colourful clothes and hair despite the white robe, mask and cap the professional used during treatment. It is possible that this appearance of professionals has arisen through the empathy and communication skills the dental students used with the children. The child who created Drawing 1a mentioned the names of the dental students who treated her.

\section{2) Power relations}

Drawings 1c and 1d (Fig. 1) show representations of the dentist and also dental instruments and equipment. The drawings in this category show children in a state of submission. The reflector lamp was represented, suggesting a threat, since it is in a superior position. Also, in the event of reaching a child's eyes, it causes discomfort and makes it difficult to see what is happening. Introducing foreign elements in the oral cavity can also represent a strong assault. The child's position in the chair, usually recumbent and open mouth, prevents the use of several of its capabilities, such as motor skills and speech, fundamental to the flexibility of the relationship. Drawing 1d (Fig. 1) represents the height difference between the professional and patient. Though this perception may indeed reflect reality, the child in the drawing seems to be lying in the dental chair, indicating that he has no choice but to open his mouth.

\section{3) Contextualisation of dental care in the child's life}

Drawing 1e (Fig. 1) is from a child who has proven to be relaxed in relation to dental care, as portrayed not only by the office and dentist, but the buildings he saw through the window. This shows that he could see beyond the dental office and includes the visit to the dentist as part of his life. However, it is important to mention that this child, because of the treatment received, was attended in a sitting position. This would ensure not only the expansion of the field of vision, but the mobility needed to relate to the environment, which can be limited when children are lying on the chair.

\section{4) Trauma}

The child who made drawing 2a (Fig. 2) was subjected to extraction of teeth 51 and 61. In his drawing he expressed all the emotional pain he suffered at seeing his two central incisors removed from his body.

The child who drew Figure $2 \mathrm{~b}$ came to the dentistry school as an emergency, complaining of tooth pain. His mother reported that he had just undergone surgery in the hospital. In his drawing, he represented only a chair, much like a hospital bed, and the reflector lamp, showing that the experience of recent hospitalisation had influenced the way he perceives dental treatment.

\section{5) Childhood resistance}

Some children subverted the initial request made by a researcher. These children, when asked to undertake the drawing about dental treatment, draw homes. The house in Figure 2c was huge and had open windows, images of a hearth and trees, representing love and life. It suggests a safe place, in contrast to the situation of dental care.

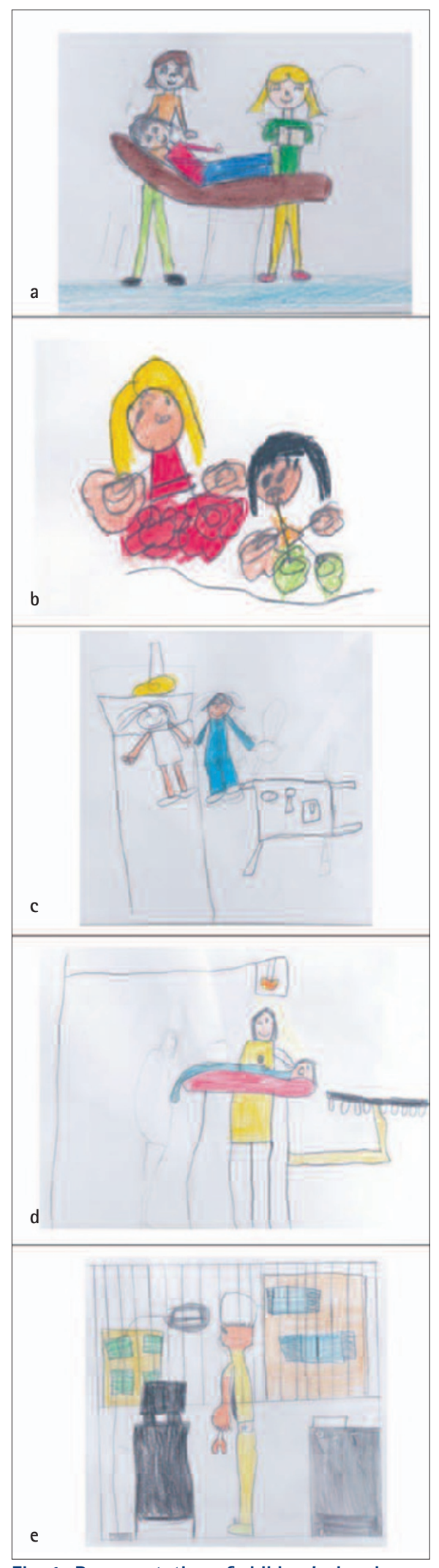

Fig. 1 Representation of children's drawings about dentistry. Personal relationship: (1a) drawing by an 8-year-old girl and (1b) drawing by a 6-year-old girl. Power relation: (1c) drawing by an 8-year-old girl and (1d) drawing by an 8-year-old boy. Contextualisation of dental care in the child's life: (1e) drawing by a 10 -year-old boy

According to the mother, the child has previously been submitted to extraction of six 


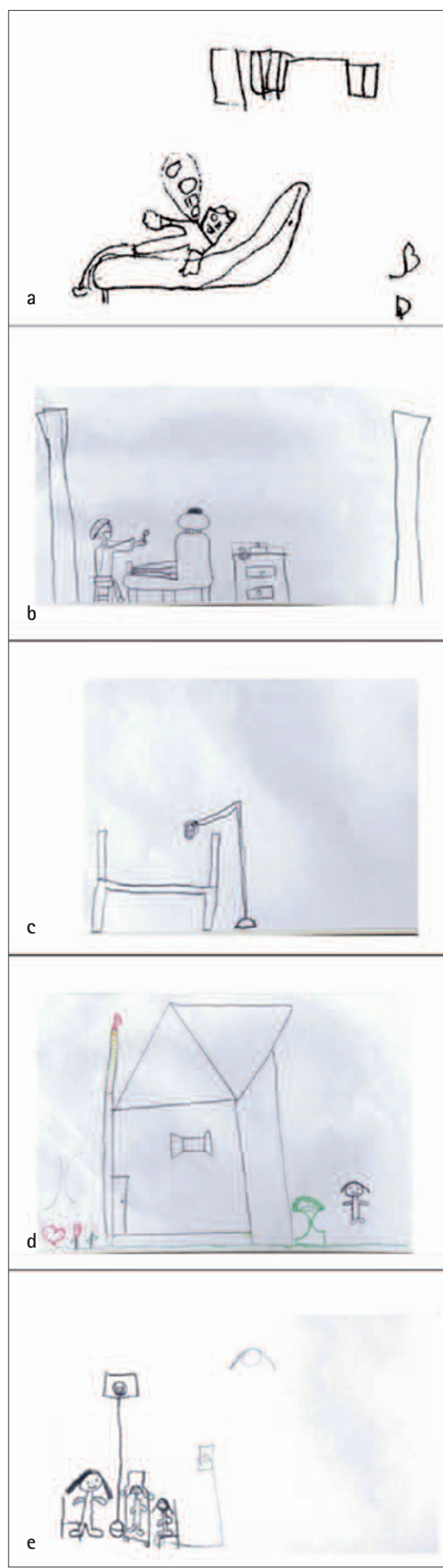

Fig. 2 Representation of children's drawings about dentistry. Trauma: (2a) drawing by a 6-year-old boy and (2b) drawing by an 8-year-old boy. Childhood resistance: (2c) drawing by an 8-year-old girl before and (2d) after instructions about the theme of the drawing were given again

deciduous teeth due to orthodontic reasons. After the directions were repeated, the child held the drawing on the theme, but the layout and size of the drawing 2d (Fig. 2) in the leaf, shows that the treatment takes up
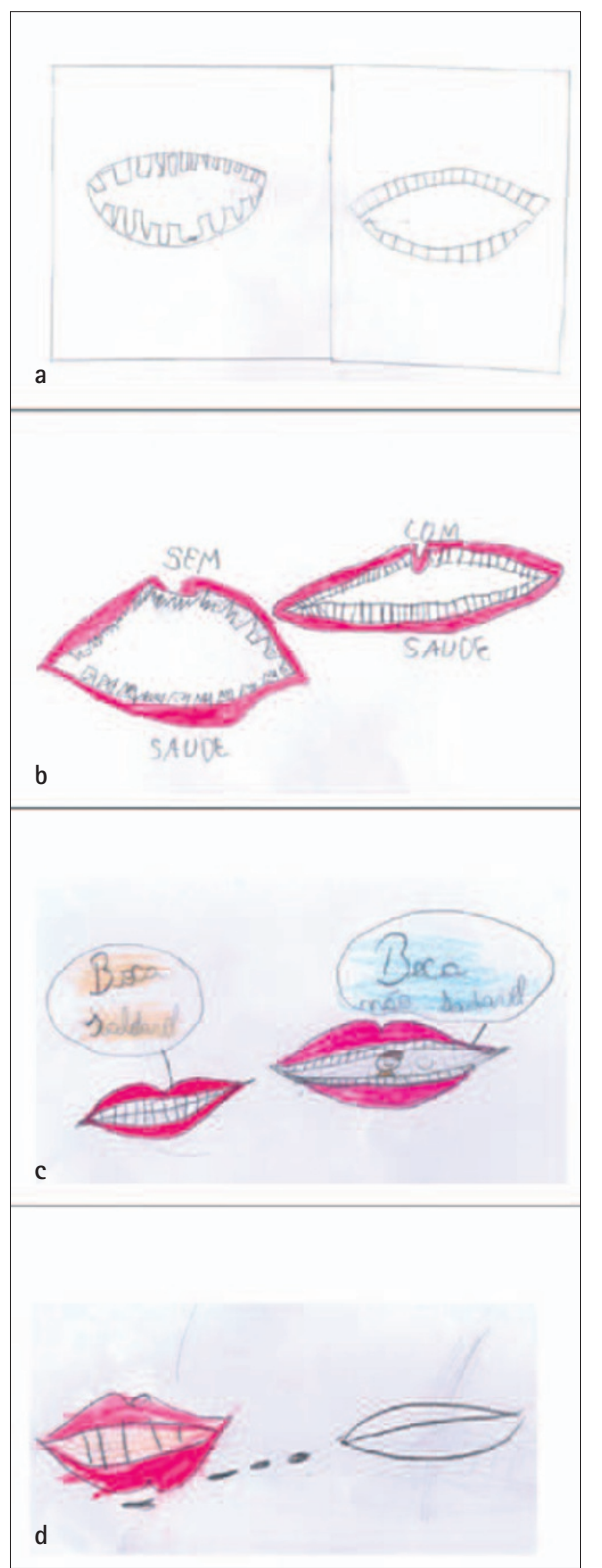

Fig. 3 Representation of children's drawings about oral health. Dichotomy of health/ sickness: (3a) drawing by a 9-year-old boy and (3b) drawing by an 8-year-old boy. Ludic representation of health: (3c) drawing by an 8-year-old boy. Sickness seen as a process: (3d) drawing by a 6-year-old girl

less space in your life. This suggests how the child is able to cope with the rules imposed by the adult world by creating your own domain space. Other children, when questioned by the researcher about why they have not represented dental care, said they preferred to draw houses.

\section{Oral health representation}

The following categories were identified by the psychologist to the oral health representation:

\section{1) Dichotomy of health/sickness}

Some children (Fig. 3a) made a watertight division between the healthy mouth and the sick mouth, separating them with a trace path. This can lead us to think about cultural representations of health and disease states as absolutely opposite, without a process of transition. The healthy mouth has straight teeth and child called it: 'beautiful', 'happy', 'clean', 'with good teeth'. On the other hand, the unhealthy mouth is considered 'dirty', 'without teeth', 'ugly', 'with fractured teeth' (Fig. 3a and 3b).

\section{2) Ludic representation of health}

The playful element, so constant in children's drawings was also represented. The child who made drawing 3c (Fig. 3) represented an unhealthy mouth with a 'bug'. While drawing, this child described her dental experience telling histories, with fantasy and imagination. Added to the fact that he never lived with 'toothache', his level of abstraction allows him to associate an unhealthy mouth with the presence of a 'bug'.

\section{3) Health-disease process}

Some children, when asked to draw a healthy and a sick mouth, have shown to perceive oral health as a process. Figure $3 \mathrm{~d}$ shows a healthy mouth with red lips smiling, and an unhealthy mouth closed, with no colour inside and with 'tooth worms' meeting the healthy mouth.

\section{DISCUSSION}

It is good for paediatric dentists to know how patients feel about dental treatment and to understand why the patients respond the way they do. ${ }^{13}$ This study suggests that projective self-report techniques such as drawings can be an appropriate way to collect information about children's perceptions and experiences. ${ }^{14}$ Drawing can be considered a way through which children can express their emotions. ${ }^{15}$ In clinical practice, drawings have commonly been used for decades by child psychiatrists and psychologists to analyse children's subjective feelings, fears and other emotions such as distress, anxiety, worry and anger. Furthermore, the creation of a drawing is an experience that is more complex than the appropriation of a word label that can be heard and memorised for recitation. ${ }^{16}$

The use of art expression is a way to bring order and containment to feelings that may be contradictory, confusing or difficult to say with words. ${ }^{17}$ Children can bring whatever they really feel to their drawings as their alternative language. ${ }^{2}$ Perhaps the most appealing clinical aspects of using drawings in assessment is that the non-verbal method transcends language limitations and cultural barriers, especially for children who lack the ability to communicate emotions verbally. It takes little time to administer and is usually an enjoyable activity. For the child who has 
experienced trauma or loss, it helps to externalise emotions and events too painful to speak out loud and is one of the only means of conveying the complexities of painful experiences, repressed memories, unspoken fears, anxieties or guilt. ${ }^{17}$

Children's art expressions, like children themselves, are individual and must be considered as such within the larger context of their developmental, emotional, social and cultural experiences. ${ }^{18}$ For Vygotsky, ${ }^{19}$ an understanding of the difference between what he termed a child's spontaneous concept and a child's scientific concept depends on one's understanding of these two assumptions. It is in the spontaneous concept, which occurs in a child's first encounter with an experience, that the referential use of language plays an important role. However, for meaning to develop further into abstraction the child has to move beyond this direct linking of reference to an object to a more generalised meaning. In Vygotsky postulations, objects are grouped into categories rather than remaining single objects, because a child's spontaneous concept differs from a child's scientific concept; particularly in the path the child takes in his or her thinking ${ }^{16}$.

The methods used in this research included the observation and analysis of drawings using Vygotskian analysis, in order to help understand the significance for children of her dental experiences. It is known that dental behaviour may be influenced by various factors: previous traumatic experiences with dentists or other health professional, pain experienced during past dental care as well as parents' own anxiety and familial attitudes. ${ }^{16,20}$ Personal relationships were represented by the inclusion of the child in the drawing and by what child said during the task, demonstrating the good relationship established with the dentist. One of the main requirements when treating children is the building of a relationship of trust with the dentist, This means that knowledge of the child's psycho-social development essential. ${ }^{21}$ Children who have positive interactions with their dentist will be less likely to develop a fear of dentists and will experience less anxiety during dentist appointments. As a result, they will be more likely to visit the dentist as adults and to have better oral health. ${ }^{22-24}$

Thus, it is important for dentists to establish a friendly relationship with patients, especially children, in order to combat patient fears and to deliver effective and efficient treatment. It is known that dental treatment is constantly associated with fear, anxiety, pain and discomfort. Children fear the dentist, the instruments and the noise associated with dental treatment. ${ }^{8}$ Also, a child will often make judgements about their dentist based on his or her appearance and often record and analyse their dentist's every word, movement and gesture during a dental appointment. A friendly relationship with the dentist can help patients cope with specific stimuli such as the sight of the anaesthetic needle and the sight, sound, and sensation of the dental handpiece and bur, which have been shown to provoke anxiety. ${ }^{1,25}$

Dental anxiety was shown by children in their drawings thorough the representation of themselves as 'immobilised' facing a situation perceived as threatening, or when children appear in the drawings lying with open and/or raised arms and threatened by the reflector lamp. Also the child's position in the chair, reclined and generally openmouthed, precludes the use of several of his/her capabilities. A universally accepted concept is that, when drawing, a child will depict their own point of view, enlarging the details they think important and creating expressionistic compositions. ${ }^{26}$ Children draw dentists taller than themselves. Anxiety may distort the actual size of the professional, so that in some drawings the dentist is much taller than the child, showing a position of superiority. Aminabadi et al. ${ }^{2}$ adopted the child drawing: hospital (CD:H) tool to analyse children's drawing in dental settings. In this scale, the smaller the child represents themselves, the higher score is attributed, indicating higher stress.

Taylor et al. ${ }^{9}$ assessed 1,101 drawings by school children and found out that dental lights have been represented abnormally in $6.9 \%$ of drawings. Forceps-like instruments were present in $11 \%$ of the drawings. A dental syringe-like instrument appeared in a realistic manner $7.1 \%$ of the time, but was judged to be abnormal in $1 \%$.

For children undergoing dental treatment, it is the internal danger associated with the dental intervention that gives rise to their dental anxiety. ${ }^{27}$ According to Sheskin et al., ${ }^{8}$ previous medical experience affects subsequent cooperation. Fear may therefore be transferred, especially if the child previously underwent surgery of any kind. In this group of patients this situation was observed. This highlights the importance of carrying out a complete anamnesis, gathering information about the behaviour of children in previous appointments and past experiences.

It is worth mentioning that none of the children represented the most common instruments used for oral health prevention: toothbrush, toothpaste and dental floss, which may suggest that more emphasis should be placed on their importance during the dental appointment. Another study found out that a certain 'positive' element, such as patient education material, appeared in some drawings. ${ }^{9}$
The attitude expressed by some children through drawing non-dental situations demands attention. It is suggested that anxious children do not draw the expected anxiety-provoking situation. ${ }^{28}$ In the study by Taylor et al., ${ }^{9}$ some children drew pictures which did not show anything reflecting dentistry, although they had been asked to make a picture of a 'dentist at work' or 'what you think about when you're at the dentist?.' However, $4.9 \%$ of the total sample consisted of pictures showing scenes not directly related to dentistry. According to the authors, this could represent what else the child was thinking about, a lack of dental experience or even a high level of anxiety that prevented the child from thinking about his dental experience. ${ }^{9}$ In our study, the child would be asked to repeat the drawing. After the instructions, however, the child placed the drawing low on the page and left-sided. According to the criteria adopted in the CD:H scale, children who feel less anxious tend to place their drawings in the center of the paper, while left-sided placement suggests orientation toward the past and placement low on the page may indicate insecurity. ${ }^{2}$

Previous studies have demonstrated the benefits of using drawing in the dental context. Arcari and Ferro ${ }^{15}$ assessed preschool children's satisfaction grading of relative analgesia when completing dental treatment by collecting their opinion on this technique through a verbal questionnaire and evaluation of drawings performed after dental treatment. They concluded that there was no evidence of traumatic emotions linked to the relative analgesia experience, as there was no over exposure of teeth or mouths on the people or animals represented in the drawings nor were there alterations in the characteristics of the dental environment (dentist and dentist's instruments).

Vale et al. ${ }^{29}$ assessed the perception of the aesthetic components of the oral health by children aged between 21 months and 11 years through assessment of drawings of 'beautiful teeth' and 'ugly teeth'. The authors found out that children of all ages could clearly represent their perception about aesthetics and concluded that drawings are a useful source of information for assessing the aesthetic perception of paediatric patients, as children are conscious about their dental aesthetic appearance and that of other children. Besides this, the visual universe, which consists of images projected by cartoons, graphics in television programmes, school books, games and toys, was entered by children in their drawings, as a ludic representation of dental health.

Aminabadi et $a .^{2}$ showed that drawing is highly correlated to both standard SEM and Frankl scales for evaluating children's distress in dentistry. Sheskin et al. ${ }^{8}$ established 
a dental anxiety scale for children using their drawings during dental treatment, evaluating six criteria in the narrative classification of Piaget's cognitive development.

There are limitations to the present study. Drawings were analysed by an experienced psychologist, based on theoretical psychological premises. In the dental office, the complete interpretation of these drawings may be difficult. A method of analysis which involves 'dissecting' a drawing by deciding if certain items are merely present or not, tends to reduce the difficulty in making judgements about what the child has drawn. This could permit more clear-cut conclusions to be made concerning children's attitudes and behaviour in relation to the acceptance of dental care. ${ }^{9}$

The purpose of identifying children's attitudes towards their dentists is to effect positive changes or adjustments that would make children more comfortable in the dentist's office and improve the quality of dental visits. ${ }^{1}$ The findings of the present study provides evidence that some aspects of the dental care of children should be discussed during dental education, such as the importance of creating a strong rapport with the child patient and understanding and dealing with the child's feelings of submission as represented in the drawings analysed. Besides possessing technical skills and scientific knowledge to treat child patients, dentists must also pay attention to children's feelings and emotions.

\section{CONCLUSION}

The present findings help to understand what children see as unpleasant aspects about going to the dentist and emphasise the importance of using drawing to facilitate communication with these patients. Drawing can be used to better understand children's emotions and expectations about dental treatment, recreating their senses, expressing their place of belonging. Dentists need to reduce children's anxiety and fear of dentistry as much as possible. Valid drawing assessment tools to measure children's distress in paediatric dental settings should be developed.

1. Alsarheed M. Children's perception of their dentists. Eur J Dent 2011; 5: 186-190.

2. Aminabadi N A, Ghoreishizadeh A, Ghoreishizadeh M, Oskouei S G. Can drawing be considered a projective measure for children's distress in paediatric dentistry? Int J Paediatr Dent 2011; 21: 1-12.

3. Barbieri C M, Frota F D S, Aguiar S M H C A. A cárie dentária e a imagem do dentista sob a ótica infantil. Revista Odontol Araçatuba 2010; 31: 16-21.

4. Driessnack M. Children's drawings as facilitators of communication: a meta-analysis. J Paediatr Nurs 2005; 20: 415-423.

5. Daniel T S, Guimarães M S, Long S M, Marotti N R L, Josgrilberg E B N. Percepção do paciente infantil frente ao ambiente odontológico. Odontol ClínCientif Recife 2008; 7: 129-132.

6. Bottan E R, Silveira E G, Odebrecht C M R, Araújo $S$ M, Farias M A G. Relação entre ansiedade ao tratamento dentário e caracterização do "dentista ideal": Estudo com crianças e adolescentes. Rev Port Estomatol Med Cir Maxilofac 2010; 51: 19-23.

7. Marshman Z, Hall M J. Oral health research with children. Int J Paediatr Dent 2008; 18: 235-242.

8. Sheskin R B, Klein H, Lowental U. Assessment of children's anxiety throughout dental treatment by their drawings. ASDC J Dent Child 1982; 49: 99-106.

9. Taylor D, Roth G, Mayberry W. Children's drawings about dentistry. Community Dent Oral Epidemiol 1976; 4: 1-6.

10. Vygotsky L S. La imaginación y la arte en la infancia Madrid: Akal, 1990

11. Klepsch M, Logie L. Children draw and tell: an introduction to the projective uses of children's human figure drawings. New York: Brunner/Mazel, 1982.

12. Piaget J. Play, dreams and imitation. New York: Norton, 1951

13. Kantaputra P N, Chiewcharnvalijkit K, Wairatpanich K, Malikaew P, Aramrattana A. Children's attitudes toward behaviour management techniques used by dentists. J Dent Child 2007; 74: 4-9.

14. Skybo T, Ryan-Wenger N, Su Y H. Human figure drawings as a measure of children's emotional status: critical review for practice. J Paediatr Nurs 2007; 22: 15-28.

15. Arcari S, Ferro R. Preschool children and relative analgesia: satisfaction grading through a verbal questionnaire. Eur J Paediatr Dent 2008; 9: 18-22.

16. Brooks M. What Vygotsky can teach us about young children drawing. IAEC Res J 2009; 1: 1-13.

17. Malchiodi C. Using drawing as intervention with traumatized children. Trauma Loss: Res Interventions 2001; 1 (1).

18. Looman W S. A developmental approach to understanding drawings and narratives from children displaced by Hurricane Katrina. J Paediatr Health Care 2006; 20: 158-166.

19. Vygotsky L. The collected works of L S. Vygotsky. New York, NY: Plenum Press; 1987.

20. Raadal M, Strand G V, Amarante E C, Kvale G Relationship between caries prevalence at 5 years of age and dental anxiety at 10. Eur J Paediatr Dent 2002; 3: 22-26.

21. Massoni A C, Ferreira J M S, Colares V, Duarte R C. Roteiro para interpretação de desenhos: facilitando a abordagem da criança no consultório odontológico. Arq Odontol 2008; 44: 31-36.

22. Bottan E R, Pelegrini F M, Stein J C, Farias M M A G, Araújo S M. Relação entre consulta odontológica e ansiedade ao tratamento odontológico: estudo com um grupo de adolescentes. RSBO 2008; 5: 27-32.

23. Colares V, Caraciolo G, Miranda A M, Araújo G V, Guerra P. Medo e/ou ansiedade como fator inibitório para a visita ao dentista. Arq Odonto/ 2004; 40: 100-110.

24. Kanegane K, Penha S S, Borsatti M A, Rocha R G. Ansiedade ao tratamento odontológico no atendimento de rotina. RGO, Porto Alegre 2006; 54: 111-114

25. Kleinknecht R A, Klepac R K, Alexander L D. Origins and characteristics of fear of dentistry. J Am Dent Assoc 1973; 86: 842-848.

26. Luquet G H. Arte infantil. Lisboa: Editora do Moinho, 1969.

27. Freeman R. A fearful child attends: a psychoanalytic explanation of children's responses to dental treatment. Int J Paediatr Dent 2007; 17: 407-418.

28. Eichenbaum I W, Dunn N A. Projective drawings by children under repeated dental stress. ASDC J Dent Child 1971; 38: 164-173.

29. Vale T, Santos P, Moreira J, Manzanares M C, Ustrell $J$ M. Perception of dental aesthetics in paediatric dentistry. Eur J Paediatr Dent 2009; 10: 110-114. 